\title{
Analysis on Topographic Effect of Soil Moisture in Mountainous Areas based on Landsat-8 OLI Images
}

\author{
Cai Qingkong1 ${ }^{1}$, Li Erjun², *, Chen Ju' ${ }^{1}$, Tao Liangliang ${ }^{3,4}$ and Jiang Ruibo ${ }^{1}$ \\ ${ }^{1}$ College of Civil Engineering, Henan Institute of Engineering, Zhengzhou 451191, China \\ ${ }^{2}$ College of Human and Social Sciences, Henan Institute of Engineering, Zhengzhou 451191, China \\ ${ }^{3}$ School of Geographical Sciences, Nanjing University of Information Science and Technology, Nanjing 210044, China \\ ${ }^{4}$ Department of Infrastructure Engineering, University of Melbourne, Parkville, Victoria 3000, Australia
}

Received 3 January 2020; Accepted 29 March 2020

\begin{abstract}
Ecological environmental worsening and water-soil loss occur frequently in mountainous areas in recent years. As an important index of land deterioration and degree of drought, soil moisture can influence vegetation growth, hydrological cycle and water resource distribution in mountainous areas significantly. However, topographic effect of soil moisture under complicated mountainous terrain conditions still remains unknown. In the present study, a quantitative inversion on surface soil moisture content in a typical mountainous area of Dengfeng city, Henan province (China) in 2013 and 2017 was carried out by using temperature vegetation dryness index method based on Landsat-8 OLI (Operational Land Imager) remote sensing images and digital elevation model (DEM). Results were conducive to analyze effects of terrain factors on spatial-temporal distribution of soil moisture and improve ecological environment in mountainous area. Besides, a quantitative analysis on topographic effect (e.g. elevation, slope and slope orientation) on soil moisture in mountainous area was performed based on DEM data. Results demonstrate that topographic factors (e.g. elevation, slope and slope orientation) can cause violent variations of soil moisture in mountainous areas. Soil moisture is positively correlated with elevation and slope. In view of slope orientations, shady slope generally presents the highest soil moisture, followed by semi-shady slope, sunny slope and semi-sunny slope successively. In 2017, the heat island effect in the study area is stronger and the arid area is significantly larger than those in 2013. Additionally, soil moisture in the region with elevation lower than $750 \mathrm{~m}$ and slope smaller than $25^{\circ}$ is lower in relative to that in 2013, but it is higher in the region with elevation higher than $750 \mathrm{~m}$ and slope larger than $25^{\circ}$. This study discloses the influencing law of terrain factors on spatial-temporal distribution of soil moisture in mountainous areas. Research conclusions provide some scientific references to water conservation and ecological environmental protection in mountainous areas.
\end{abstract}

Keywords: Soil moisture, Terrain factor, Mountainous areas, Temperature vegetation dryness index

\section{Introduction}

As an important component of water cycle of terrestrial ecosystems, soil moisture is a comprehensive reflection of natural conditions, including climate, vegetation, terrain and soil factors. Moreover, soil moisture is an important index to measure land deterioration and degree of drought, especially in complicated mountainous areas. Due to topographic relief, surface moisture, energy and other key elements have uneven spatial distributions in mountainous areas, which further influences vegetation growth, water resource distribution and local microclimate [1-4]. Therefore, studying spatial-temporal distribution characteristics of soil moisture in mountainous areas has important scientific and practical significance to ecological environmental protection in mountainous area.

In existing soil moisture monitoring methods, optical remote sensing and microwave remote sensing are the most potential two quantitative monitoring methods of soil moisture [5-8]. With strong penetration through clouds, fogs and surface, microwave remote sensing can offer services $24 \mathrm{~h}$ a day and under all weather conditions, and it enjoys

\footnotetext{
*E-mail address: hnwxlei@163.com

ISSN: 1791-2377 @ 2020 School of Science, IHU. All rights reserved.

doi:10.25103/jestr.132.04
}

promising application prospects in soil moisture monitoring. Khedri et al. [9] implemented inversion of surface soil moisture by using a support vector machine (SVM) regression model based on AIRSAR data of wavebands $C, L$ and $\mathrm{P}$ in 2003. Based on SAR image data, Holtgrave et al. [10] calculated influences of compensation vegetation of normalized differential vegetation index (NDVI) on backscatter of SAR images by using Landsat- 8 data. They have achieved good results from inversion of soil moisture in flooding regions based on SVM model. However, these studies have a high research cost due to the expensive radar images. Moreover, radar images are sensitive to terrain, surface roughness, vegetation coverage and topographic parameters. Radar parameters have complicated relations with the target characteristic parameters. These disadvantages restricted the wide application of radar image to some extent [11]. Optical remote sensing has certain penetrating power to soil layer and it can extract soil moisture information in superficial layers to provide references for drought monitoring, vegetation growth and improvement of ecological environment. The temperature vegetation dryness index ( TVDI ) is an extensively used method which has relatively mature theory on remote sensing monitoring of soil moisture based on visible light and thermal infrared band. TVDI method couples the 
surface temperature $\left(T_{s}\right)$ and vegetation index ( NDVI ) and realizes quantitative inversion of soil moisture through changing characteristics of $T_{s}-N D V I$ characteristic space. This method decreases parameters for soil moisture inversion and has a low research cost. Currently, TVDI method has achieved some success in soil moisture inversion, drought monitoring and crop output estimation in different spatial scales [9, 10, 12-15]. Spatial distribution of soil moisture is mainly influenced by meteorological factors (e.g. precipitation, solar radiation and air temperature), underlying properties (e.g. physical properties of soil, surface vegetation and land use) and topographic conditions (e.g. slope, slope orientation, elevation and slope position) [16]. Yisok et al. [17] taking the bare soil experimental area as an example, retrieved the soil moisture content based on the microwave remote sensing data, and achieving a high accuracy. Lievens et al. [18] carried out a soil moisture inversion in the vegetation coverage regions with underlying vegetation based on $\mathrm{HH}$ polarization data of ALOS/PALSAR radar by combining water-cloud model and effective roughness parameters, and the lowest inversion error was close to $5.5 \mathrm{vol} \%$. However, terrain factors are important factors that influence spatial distribution of soil moisture in complicated mountainous regions in addition to meteorological factors and underlying properties. Currently, a series of studies on land use, vegetation coverage and drainage basin distribution based on terrain factors have been reported. $\mathrm{Wu}$ et al. [19] analyzed terrain gradient characteristics of ecological land use changes in plateau regions on dams from perspectives of elevation, slope and slope orientation. They found that distribution of ecological land use in plateau regions on dams was significantly sensitive to terrain factors. These studies mainly discuss terrain gradient characteristics of ecological land use, but have not discussed influences of terrain on soil moisture distribution. Tian et al. [20] analyzed influences of slope position on soil moisture and spatial vegetation distribution in Inner Mongolia grassland, and disclosed an order of different slopes with respect to average soil moisture in the 0-50 cm soil layer: slope bottom $>$ shady slope $>$ sunny slope and slope top. This study mainly analyzed influences of slope position on soil moisture distribution, but it didn't investigate influences of slope and slope orientation on soil moisture distribution. Luo [21] analyzed the relationship between soil moisture and terrain factors in a small-scaled sampling region, finding a negative correlation between soil moisture and slope. The highest soil moisture was on the east slope, followed by the northeast slope. However, this study involved a small study area and soil moisture was gained through interpolation of sampling points, which was different from terrain in mountainous region to some extent.

Although there are many studies on soil moisture and the application fields are extensive, these studies mainly focus on single aspects, such as inversion method of soil moisture, influencing factor of soil moisture, etc. Therefore, it is necessary to strengthen not only studies on topographic effect and spatial-temporal distribution features of soil moisture in complicated mountainous areas, but also strengthen ecological environmental governance in mountainous areas based on research results. Based on existing scientific understanding and research results, this study further explored topographic effect and spatialtemporal distribution laws of soil moisture in Dengfeng city which is a complicated mountainous region in China from perspectives of elevation, slope and slope orientation. In this study, surface temperature, soil moisture and terrain factors in the study area were used as the main research indexes. Research conclusions can provide some scientific references to improve ecological environment in mountainous region.

The reminder of this study is organized as follows. Section 2 introduces the study area, preprocessing of remote sensing images and terrain factors, as well as inversion method of surface temperature and soil moisture. Section 3 is a quantitative inversion of surface temperature and soil moisture in the study area through radiation transfer method and TVDI method, which discloses the spatial-temporal distribution laws of surface temperature and soil moisture. In addition, influencing laws of elevation, slope and slope orientation on distribution of soil moisture are analyzed. Countermeasures to improve ecological environment in mountainous region are proposed by combining relevant results. Section 4 summarizes conclusions.

\section{Materials and methods}

\subsection{Study area}

The study area was chosen at Dengfeng city $\left(112^{\circ} 49^{\prime} \sim\right.$ $\left.113^{\circ} 19^{\prime} \mathrm{E}, 34^{\circ} 35^{\prime} \sim 34^{\circ} 15^{\prime} \mathrm{N}\right)$, which was subordinated to Zhengzhou city, Henan province, China. The study area is next to Xinmi in the east, Yichuan county in the west, Yuzhou city and Ruzhou city in the south, and Yanshi city and Gongyi city in the north. It is $58 \mathrm{~km}$ long from the east to west, and $36 \mathrm{~km}$ wide from south to north, covering an area of $1220 \mathrm{~km}^{2}$. Elevation of this study area ranges between 156 1459 $\mathrm{m}$. Dengfeng city has significant different terrains and great topographic relief. There is Songshan in the north, and Jishan and Xiongshan in the south, all of which run from east to west. The general terrain declines to hills and rivers from north-south to middle gradually. According to terrains, the study area can be divided into deep mountains, shallow mountains, hills and flat regions. Among them, the deep mountains account for $17 \%$ of total area in the Dengfeng city, while shallow mountains, hills and flat regions account for $30 \%, 36 \%$ and $17 \%$ of total areas, respectively. Slopes of hills are mainly larger than $6^{\circ}$. Dengfeng city belongs to warm temperate continental monsoon climate and there are four distinctive seasons, with great temperature differences. The annual average sunshine duration is 2297 hours. The annual average temperature is $14.2^{\circ} \mathrm{C}$, with extreme temperatures of $40.5^{\circ} \mathrm{C}$ and $-15.1^{\circ} \mathrm{C}$, respectively. The frost-free season lasts for 238 days in a year and the annual average precipitation is 614 $m m$.

\subsection{Data acquisition and preprocessing}

Data used in this study included Landsat-8 OLI remote sensing image data and DEM data in winter of 2013 and 2017.

\subsubsection{Satellite remote sensing data and preprocessing}

In this study, Landsat-8 OLI remote sensing data were downloaded from the website of geographic space data cloud platform (http//:www.gscloud.cn) on December 29th, 2013 and on December 24th, 2017. Spatial resolution of images was $30 \mathrm{~m}$. Image stripe number was $124 / 036$. The longitude and latitude of image centers were $113.45752^{\circ}$ and $34.61065^{\circ}$, respectively. The mean cloudiness was lower than $10 \%$. Preprocessing of Landsat-8 OLI images was mainly implemented in ENVI5.3, including radiometric calibration, atmospheric correction, image registration and 
Cai Qingkong, Li Erjun, Chen Ju, Tao Liangliang and Jiang Ruibo/

Journal of Engineering Science and Technology Review 13 (2) (2020) 22 - 29

image cropping. Specifically, radiometric calibration of image data was realized by the command of radiometric calibration, and atmospheric correction of radiance data was performed by the command of FLAASH atmospheric correction. Subsequently, remote sensing images in 2017 were used as the benchmark and remote sensing images in 2013 were applied for registration. Finally, image cropping was conducted based on vector data of administrative zoning in Dengfeng city, thus getting remote sensing image data of the study area. Meanwhile, conventional meteorological data at satellite transition were collected.

\subsubsection{Data of terrain factors and preprocessing}

Terrain factor data in this study mainly covered data about elevation, slope and slope orientation. The DEM data in this study was downloaded from the geographic space data cloud platform (http//:www.gscloud.cn) and spatial resolution of images was $30 \mathrm{~m}$. Since elevation of the study area ranged between 156 1459 $\mathrm{m}$, DEM was divided into 5 levels at an interval of $250 \mathrm{~m}:<250 \mathrm{~m}, 250 \sim 500 \mathrm{~m}, 500 \sim 750 \mathrm{~m}$, $750 \sim 1000 \mathrm{~m}$ and $>1000 \mathrm{~m}$. Slope data was gained from DEM processing by using Slope tools in ArcGIS10.2. According to regulations in General Rules for Comprehensive Governance and Planning of Soil and Water Retention (GB/T 15772-2008), slope data were divided into five levels, including flat slope $\left(<5^{\circ}\right)$, gentle slope $\left(5^{\circ} \sim 15^{\circ}\right)$, relatively gentle slope $\left(15^{\circ} \sim 25^{\circ}\right)$, abrupt slope $\left(25^{\circ} \sim 35^{\circ}\right)$ and extremely abrupt slope $\left(>35^{\circ}\right)$. Slope orientation data was gained from processing of DEM data by using Aspect tool in ArcGIS10.2 and it was also divided into five levels: flat slope $\left(-1^{\circ}\right)$, sunny slope $\left(135^{\circ} \sim 225^{\circ}\right)$, shady slope $\left(315^{\circ} \sim 45^{\circ}\right)$, semi-sunny slope $\left(90^{\circ} \sim 135^{\circ}\right.$ and $\left.225^{\circ} \sim 270^{\circ}\right)$ and semi-shady slope $\left(45^{\circ} \sim 90^{\circ}\right.$ and $\left.270^{\circ} \sim 315^{\circ}\right)$. Terrain factor data were cropped by the vector data of administrative zoning in the study area, thus getting elevation, slope and slope orientation diagrams of the study area (Fig.1).

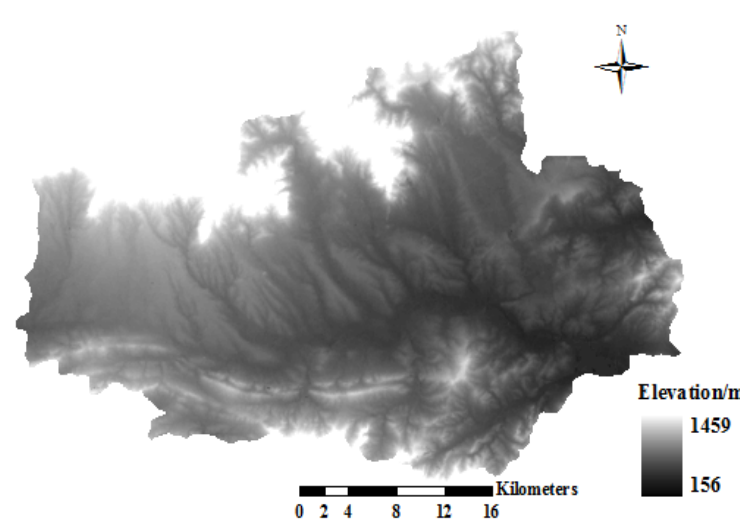

(a)

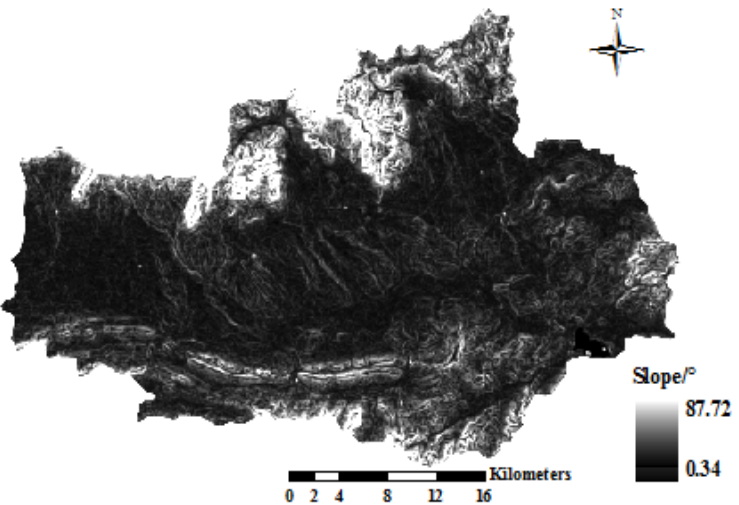

(b)

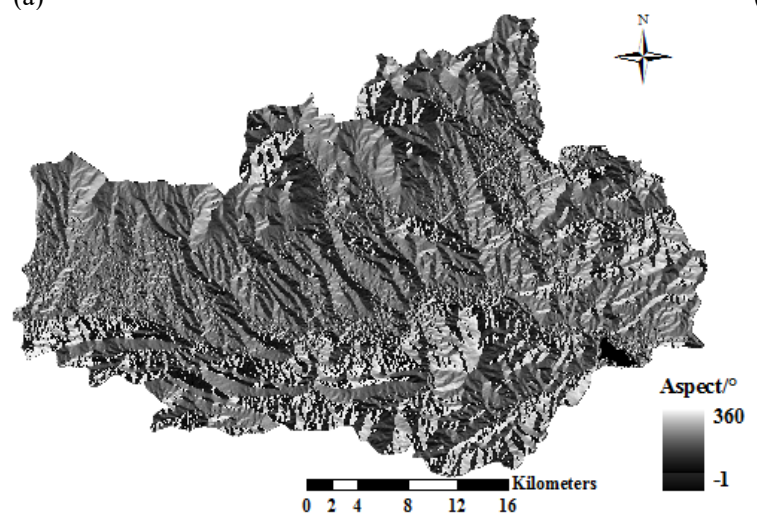

(c)

Fig. 1. Terrain factor diagrams of the study area. (a) Elevation diagram. (b) Slope diagram. (c) Slope orientation diagram

\subsection{Surface temperature inversion based on radioactive transfer equation}

Surface temperature in the study area was inversed by radioactive transfer equation (RTE). RTE, or known as atmospheric correction method, calculates effects of atmosphere on surface thermal radiation in the atmospheric radioactive transfer model according to real-time atmospheric sounding data or standard atmospheric profile, and then corrects results to real surface temperature

When the surface temperature is $T_{s}$, which can be gained from the deformed RTE:

$B\left(T_{s}\right)=\left(L-L_{a t m}^{\uparrow}-\tau(1-\varepsilon) L_{a t m}^{\downarrow}\right) / \tau \varepsilon$ according to surface specific radiation [22]. The calculation formula is:

$$
T_{s}=K_{2} / \ln \left[1+K_{1} / B\left(T_{s}\right)\right]
$$

where $T_{s}$ is the surface temperature $(\mathrm{K}) . K_{1}$ and $K_{2}$ are constants, where $K_{1}=774.81 \mathrm{~W} \cdot \mathrm{m}^{-2} \cdot \mathrm{sr} \cdot \mu \mathrm{m}^{-1} \quad$ and $K_{2}=1321.08 K \cdot B\left(\mathrm{~T}_{S}\right)$ is the Planck black-body radiance where $L$ is the spectral radiance of thermal infrared waveband which is received by the sensor. $L_{\text {atm }}^{\uparrow}, L_{\text {atm }}^{\downarrow}$ and $\tau$ are ascending and descending radiances of atmosphere as well as atmosphere transmissivity. $\varepsilon$ is the surface specific 
Cai Qingkong, Li Erjun, Chen Ju, Tao Liangliang and Jiang Ruibo/

Journal of Engineering Science and Technology Review 13 (2) (2020) 22 - 29

radiance which is estimated by the method proposed by Sobrino [22] and Qin [23]. The calculation formula is:

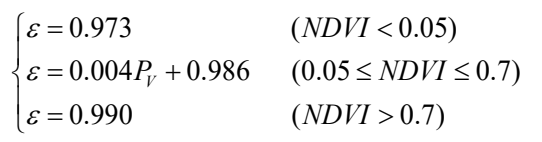

where $N D V I$ refers to the normalized difference vegetation index, and $P_{V}$ is the vegetation coverage and it is determined according to $N D V I$. The calculation formula is:

$$
\begin{aligned}
& P_{V}=\left[\left(N D V I-N D V I_{\text {soil }}\right) /\left(N D V I_{\text {veg }}-N D V I_{\text {soil }}\right)\right]^{2} \\
& N D V I=\left(\rho_{\text {nir }}-\rho_{\text {red }}\right) /\left(\rho_{\text {nir }}+\rho_{\text {red }}\right)
\end{aligned}
$$

where $N D V I_{\text {soil }}$ and $N D V I_{\text {veg }}$ are $N D V I$ values of pixels of pure naked soil and pure vegetation. $\rho_{\text {nir }}$ is the reflectance of near infrared band and $\rho_{\text {red }}$ is the reflectance of infrared band.

\subsection{Soil moisture inversion based on TVDI}

Soil moisture inversion was conducted by temperature vegetation dryness index ( TVDI ). TVDI method was proposed by Sandholt [8]. When they were simplifying the characteristic space from a trapezoid into a triangle based on existing $T_{s}-N D V I$ trapezoid characteristic space. TVDI method not only decreases parameters for soil moisture inversion, but also saves accumulation of years of historical image data, thus claiming a low cost. The calculation formula of $T V D I$ is:

$$
\begin{aligned}
& T V D I=\left(T_{s}-T_{s \text { min }}\right) /\left(T_{s \text { max }}-T_{s \text { min }}\right) \\
& T_{s \text { min }}=a_{1}+b_{1} \cdot N D V I \\
& T_{s \text { max }}=a_{2}+b_{2} \cdot N D V I
\end{aligned}
$$

where $T_{s}$ is surface temperature, $T_{s \min }$ is the minimum surface temperature $\left({ }^{\circ} \mathrm{C}\right)$ under the same NDVI conditions, that is, the wet edge of the $T_{s}-N D V I$ characteristic space. $T_{s \max }$ is the maximum surface temperature $\left({ }^{\circ} \mathrm{C}\right)$ under the same NDVI conditions, that is, the dry edge of the $T_{s}-N D V I$ characteristic space.

Eqs.(7) and (8) were brought into the Eq. (6), thus getting the calculation formula of TVDI :

$$
T V D I=\frac{T_{s}-\left(\mathrm{a}_{1}+b_{1} \cdot N D V I\right)}{\left(\mathrm{a}_{2}+b_{2} \cdot N D V I\right)-\left(\mathrm{a}_{1}+b_{1} \cdot N D V I\right)}
$$

where $a_{1}, b_{1}, a_{2}$ and $b_{2}$ are coefficient of fitting equations of dry and wet edges, respectively. TVDI value of dry edge is 1 , while TVDI value of wet edge is 0 . TVDI value is negatively correlated with soil moisture.

\section{Results and discussions}

\subsection{Spatial-temporal distribution changes of surface temperatures}

According to Spatial-temporal distribution changes of surface temperature in 2013 and 2017 were discussed through data preprocessing in Section 2.2 and the surface temperature inversion based on RTE in Section 2.3. During surface temperature inversion, values of $L_{\text {atm }}^{\uparrow}, L_{\text {atm }}^{\downarrow}$ and $\tau$ of remote sensing images in two periods still can be gained by inputting the imaging time and central longitude and latitude. $L_{\text {atm }}^{\uparrow}, L_{\text {atm }}^{\downarrow}$ and $\tau$ of remote sensing images valued $0.10,0.18$ and 0.98 in 2013, as well as $0.16,0.29$ and 0.97 in 2017. Due to lack of spectral data of pure naked soil and pure vegetation in the study area, empirical values $N D V I_{\text {soil }}=0.05$ and $N D V I_{\text {veg }}=0.70$ were applied as $N D V I$ values of pixels of pure naked soil and pure vegetation to estimate vegetation coverage. Based on RTE inversion, the surface temperature of the study area was gained from above data. Results are shown in Fig. 2.

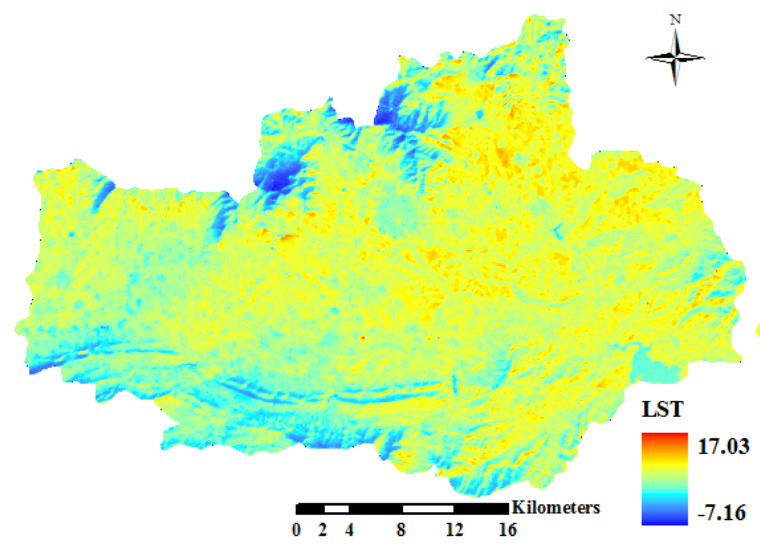

(a)

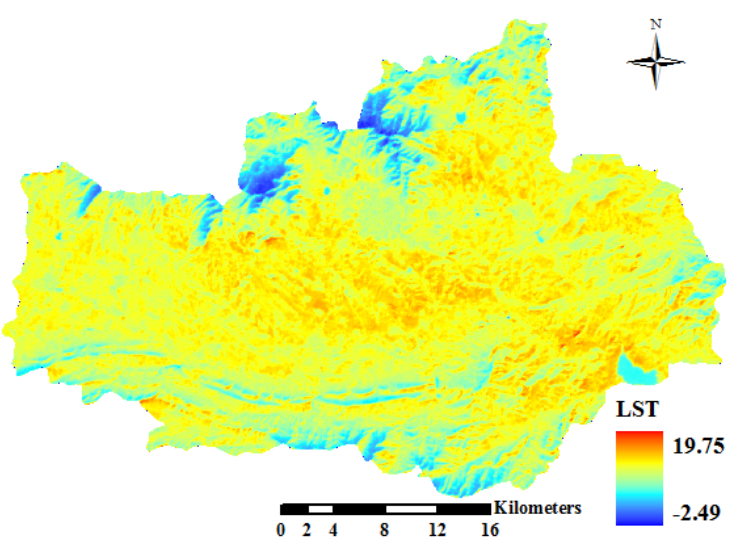

(b)

Fig. 2. Spatial distribution of surface temperature in the study area. (a) Surface temperature in 2013. (b) Surface temperature in 2017

It can be seen from Fig. 2 that surface temperature in the study area ranged between $-7.16^{\circ} \sim 17.03^{\circ}$ in 2013 , and it concentrated at $0^{\circ} \sim 10^{\circ}$ in most regions. Temperature changed greatly in the whole study area. There's relatively low temperature in north and southwest edges of the study area, but relatively high temperature in the center and north regions. Surface temperature in urban area of Dengfeng city was about $10^{\circ}$ higher than that in surrounding rural areas and 
Cai Qingkong, Li Erjun, Chen Ju, Tao Liangliang and Jiang Ruibo/

Journal of Engineering Science and Technology Review 13 (2) (2020) 22 - 29

suburbs, showing evident urban heat island effect. In 2017, surface temperature was between $-2.49^{\circ} \sim 19.75^{\circ}$ and it mainly concentrated within $5^{\circ} \sim 15^{\circ}$ in most regions. Besides, surface temperature increased gradually from south and north to center. The surface temperat2ure in 2017 was significantly higher than that in 2013. The distribution area of high temperature expanded significantly, indicating that the urban heat island effect was strengthened significantly. In addition, surface temperature in north and southwest edges of the study area was relatively low due to the low solar radiation and air temperature in winter.

\subsection{Spatial-temporal variations of soil moisture}

According to data preprocessing in Section 2.2, surface temperature inversion based on RTE in Section 2.3 and soil moisture inversion based on TVDI in Section 2.4, spatialtemporal variation characteristics of soil moisture in 2013

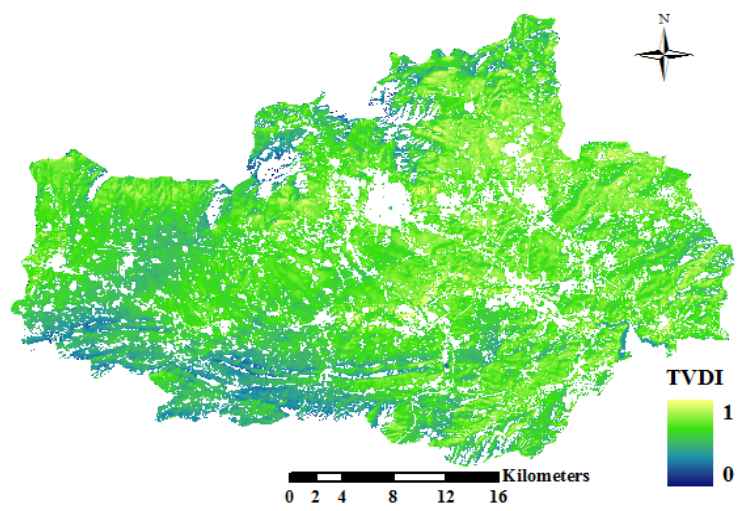

(a)

Fig. 3. Spatial distribution of $T V D I$ in the study area.(a) $T V D I$ in 2013. (b) $T V D I$ in 2017

In the study area, numerical value of $T V D I$ ranged between $0 \sim 1$. TVDI was used as the drought grading index and it was divided into five levels [4]: wet $(0<T V D I \leqslant 0.2)$, normal $(0.2<T V D I \leqslant 0.4)$, slightly drought $(0.4<T V D I \leqslant$ and 2017 were discussed in this section. Based on the inversed surface temperature and $N D V I$, the fitting equation of dry and wet edges of TVDI characteristic space were calculated in the ENVI5.3-IDL environment by using ZONALMAX and ZONALMIN functions. According to principle of $T V D I$, the calculated equations of dry and wet edges were brought to the Eq.(9), thus getting spatial distribution of TVDI in the study area. Moreover, water and urban land in the study area were extracted by supervised classification technique to reduce their influences on analysis results. Mask document was prepared to hide water and urban land in the study area. Subsequently, soil moisture of natural surface types was analyzed. The spatial distribution of TVDI in the study area after masking is shown in Fig. 3.

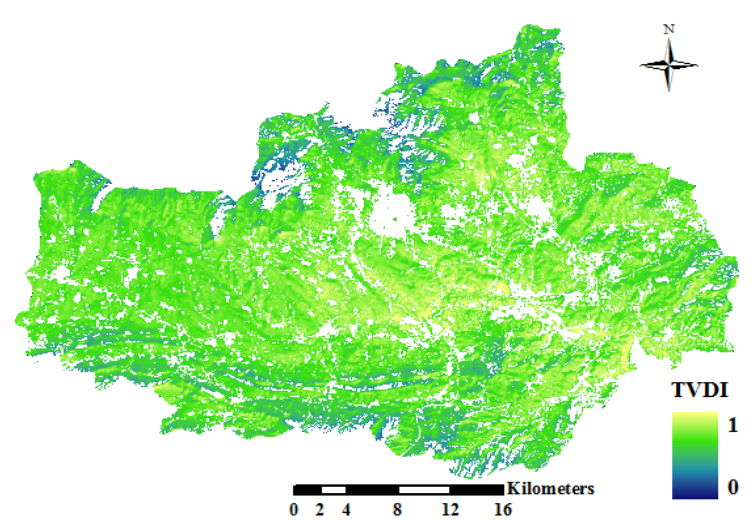

(b)

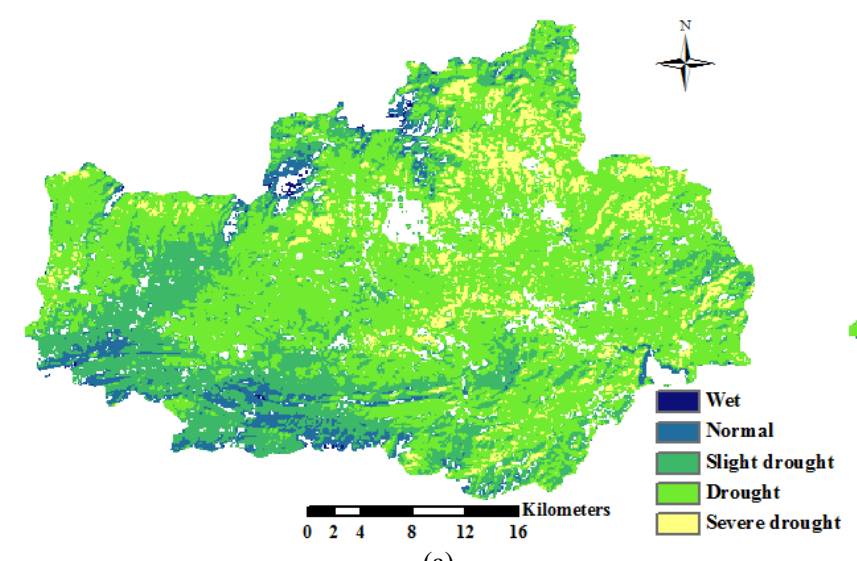

(a)
$0.6)$, drought $(0.6<T V D I \leqslant 0.8)$, and severe drought $(0.8<T V D I \leqslant 1)$. Results are shown in Fig.4. In addition, a statistical analysis on number of pixels in each level and proportions was carried out. Results are listed in Table 1.

Fig. 4. TVDI grading of the study area.(a) 2013. (b) 2017

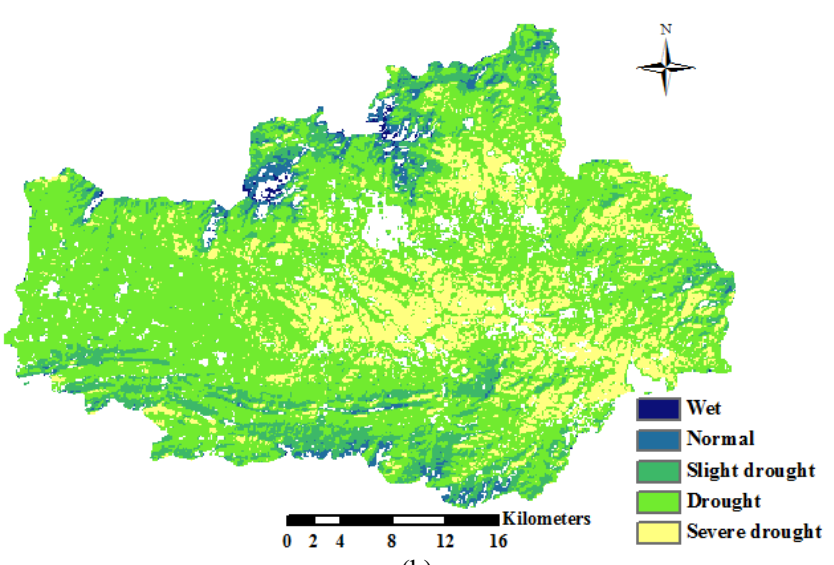

(b)

Table 1. Statistics on TVDI grading of the study area

\begin{tabular}{|c|c|c|c|c|}
\hline$T V D I$ value & Year & Number of pixels & Percentage & Soil moisture level \\
\hline $0<\mathrm{TVDI} \leqslant 0.2$ & $\begin{array}{l}2013 \\
2017\end{array}$ & $\begin{array}{l}1008 \\
1443\end{array}$ & $\begin{array}{l}0.09 \% \\
0.14 \%\end{array}$ & Wet \\
\hline $0.2<\mathrm{TVDI} \leqslant 0.4$ & $\begin{array}{l}2013 \\
2017 \\
\end{array}$ & $\begin{array}{l}51930 \\
23077\end{array}$ & $\begin{array}{l}4.89 \% \\
2.17 \% \\
\end{array}$ & Normal \\
\hline $0.4<\mathrm{TVDI} \leqslant 0.6$ & $\begin{array}{l}2013 \\
2017 \\
\end{array}$ & $\begin{array}{l}297513 \\
169938 \\
\end{array}$ & $\begin{array}{c}28 \% \\
15.99 \%\end{array}$ & Slightly drought \\
\hline $0.6<\mathrm{TVDI} \leqslant 0.8$ & $\begin{array}{l}2013 \\
2017\end{array}$ & $\begin{array}{l}631226 \\
691015\end{array}$ & $\begin{array}{c}59.4 \% \\
65.03 \%\end{array}$ & Drought \\
\hline $0.8<\mathrm{TVDI} \leqslant 1.0$ & $\begin{array}{l}2013 \\
2017 \\
\end{array}$ & $\begin{array}{c}81006 \\
177210 \\
\end{array}$ & $\begin{array}{c}7.62 \% \\
16.68 \% \\
\end{array}$ & Severe drought \\
\hline
\end{tabular}


It can be seen from Fig. 4 and Table 1 that drought area had an extensive distribution range in 2013 and 2017, which accounted for a high percentage of the study area $(59.4 \%$ in 2013 and 65.03\% in 2017). Drought areas were mainly in the Midwest and south regions of the study area. Slightly drought areas ranked the second, followed by severe drought areas and normal areas. Wet area accounted for the smallest percentage of the study, which was only $0.09 \%$ in 2013 and $0.14 \%$ in 2017. Wet areas were mainly in north and southwest regions of the study area. Severe drought area in 2017 increased by as high as $9.06 \%$ compared with that in 2013. The increased severe drought areas were mainly in middle and east regions of the study area. The drought area ranked the second in expansion and wet region was expanded slightly. However, normal region and slight drought area were narrowed significantly. Specifically, the slightly drought area was decreased the mostly by $12.01 \%$. According to comparison of two images and data statistics, soil moisture in the study area decreased continuously from 2013 to 2017, while the drought area region increased continuously.

\subsection{Effects of terrain factors on soil moisture distribution in mountainous areas}

\subsubsection{Effects of elevation on soil moisture distribution in} mountainous areas

Based on elevation grading in Section 2.2 and soil moisture inversion results in Section 2.4, the influencing law of elevation on soil moisture distribution in mountainous region was disclosed by analyzing soil moisture in different elevation levels. Elevation grading diagram was overlapped with the TVDI diagrams in 2013 and 2017 to make statistics on mean TVDI in different elevation levels. Meanwhile, the relation curve between TVDI and elevation was drawn (Fig.5).

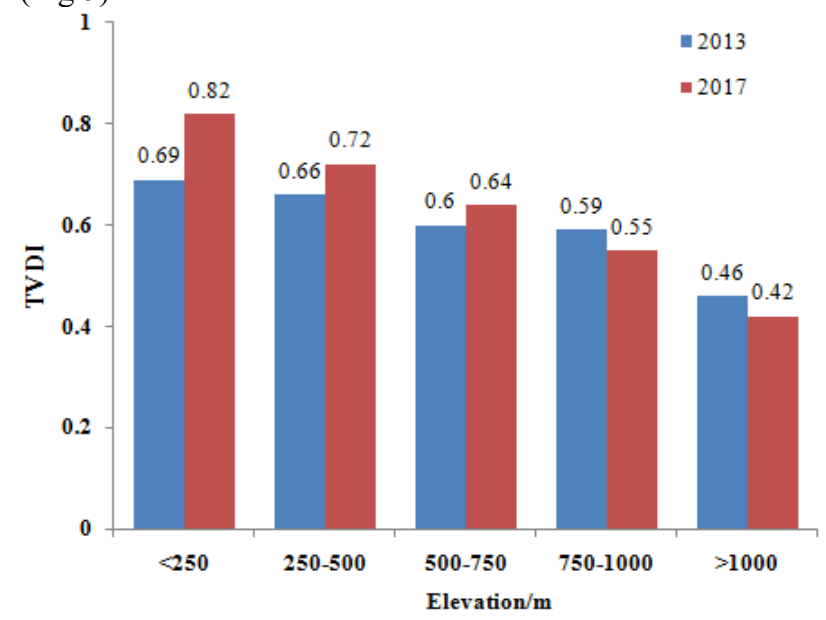

Fig. 5. Relation curve between TVDI and elevation

It can be seen from Fig.6 that TVDI value decreased gradually with the increase of elevation. In other words, soil moisture increased gradually with the increase of elevation. The lowest soil moisture was in the region with elevation lower than $250 \mathrm{~m}$, where the TVDI value was the highest, reaching 0.69 in 2013 and 0.82 in 2017 . The highest soil moisture was in the region with elevation higher than 1000 $\mathrm{m}$, where the TVDI value was the lowest, 0.46 in 2013 and 0.42 in 2017. In regions with different elevations $(<250 \mathrm{~m}$, 250 500 $\mathrm{m}$ and 500 750 m), TVDI values in 2017 were higher than those in 2013, indicating that soil moisture in
2017 was lower than that in 2013. In particular, the maximum difference $(0.13)$ of soil moisture between 2013 and 2017 was detected in the region with elevation smaller than $250 \mathrm{~m}$. In the $750 \sim 1000 \mathrm{~m}$ region and $>1000 \mathrm{~m}$ region, TVDI values were similar in 2017 and 2013. Generally, TVDI value in 2017 was lower than that in 2013, indicating that soil moisture increased from 2013 to 2017.

\subsubsection{Effects of slope on soil moisture distribution in mountainous areas}

Based on elevation grading in Section 2.2 and soil moisture inversion results in Section 2.4, the influencing law of slope on soil moisture distribution in mountainous region was disclosed by analyzing soil moisture in different slope levels. Slope grading diagram was overlapped with the TVDI diagrams in 2013 and 2017 to make statistics on mean TVDI in different slope levels. Meanwhile, the relation curve between TVDI and slope was drawn (Fig. 6).

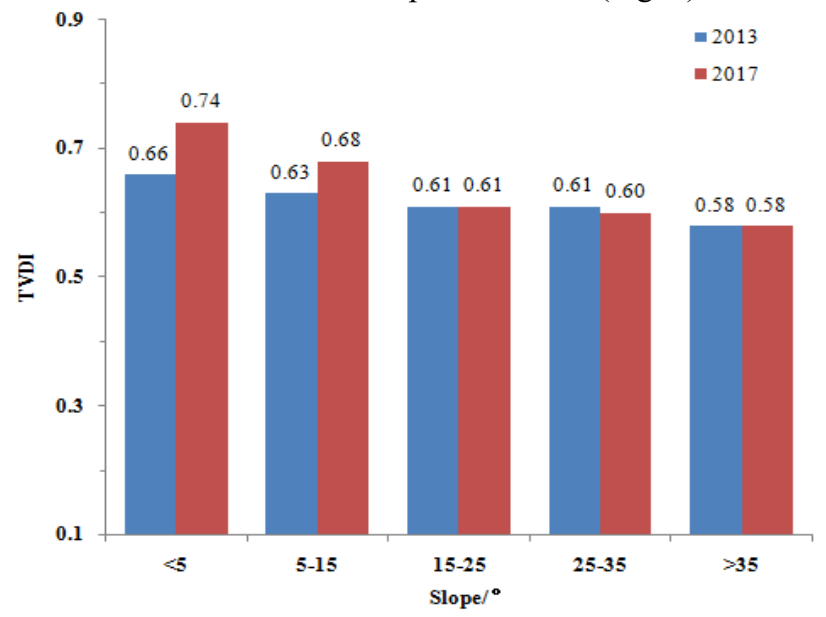

Fig. 6. Relation curve between $T V D I$ and slope

In Fig.6, TVDI value in 2013 and 2017 declined gradually with the increase of slope. The lowest soil moisture was in the region with slope smaller than $5^{\circ}$, accompanied with the highest TVDI value, reaching 0.66 in 2013 and 0.74 in 2017 . The highest soil moisture was in the region with slope higher than $35^{\circ}$, while the TVDI values were the lowest, which was 0.58 in 2013 and 2017. In region with slopes of $5^{\circ}$ and $5^{\circ} \sim 15^{\circ}$, TVDI values in 2017 were higher than those in 2013 , indicating that soil moisture in 2017 decreased than that in 2013. In particular, soil moisture in the region with slope smaller than $5^{\circ}$ showed the highest difference $(0.08)$ between 2013 and 2017. In regions with slopes of $15^{\circ} \sim 25^{\circ}$ and $>35^{\circ}$, TVDI value in 2017 was equal to that in 2013. In the region with slope of $25^{\circ} \sim 35^{\circ}, T V D I$ value in 2017 was slightly lower than that in 2013 . Generally speaking, soil moisture increased gradually with the increase of slope. Soil moisture in the $<25^{\circ}$ region in 2017 was lower than that in 2013 , but the soil moisture in regions $>25^{\circ}$ in 2017 was higher compared to those in 2013.

\subsubsection{Effects of slope orientation on soil moisture} distribution in mountainous areas

Based on elevation grading in Section 2.2 and soil moisture inversion results in Section 2.4, the influencing law of slope orientation on soil moisture distribution in mountainous region was disclosed by analyzing soil moisture in different slope orientations. Slope orientation grading diagram was overlapped with the TVDI diagrams in 2013 and 2017 to 
Cai Qingkong, Li Erjun, Chen Ju, Tao Liangliang and Jiang Ruibo/

Journal of Engineering Science and Technology Review 13 (2) (2020) 22 - 29

make statistics on mean TVDI in different slope orientations. Meanwhile, the relation curve between TVDI and slope orientation was drawn (Fig.7).

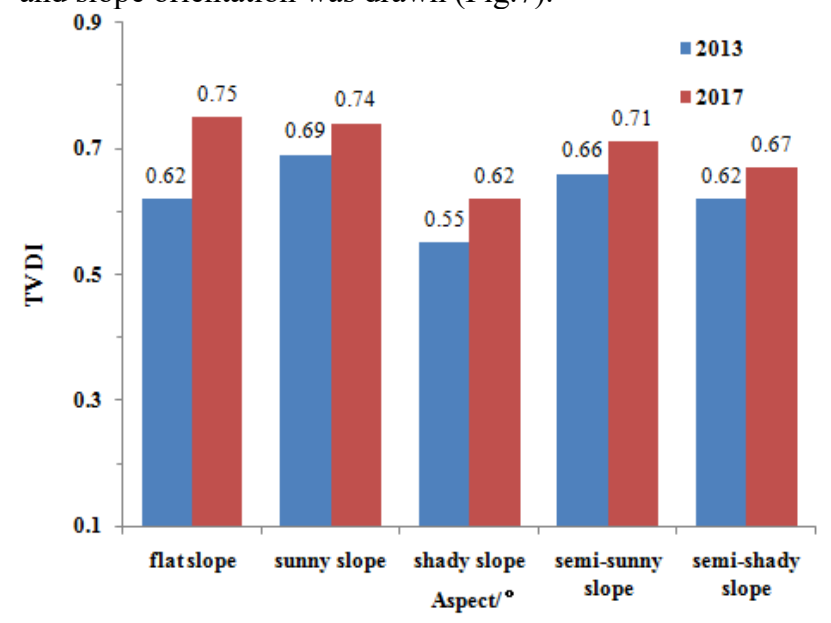

Fig. 7. Relation curve between $T V D I$ and slope orientation

Fig. 7 shows that except for the flat slope, the highest TVDI value was achieved on sunny slope in 2013 and 2017, which were 0.69 in 2013 and 0.74 in 2017. TVDI values on semi-sunny slope and semi-shady slope were the second highest. The lowest TVDI values were on the shady slope, which were 0.55 in 2013 and 0.62 in 2017. This reflected that soil moisture on shady slope was the highest, followed by those on semi-shady slope and semi-sunny slope, and then sunny slope successively. In other words: there's an order of soil moisture: shady slope $>$ semi-shady slope $>$ semi-sunny slope $>$ sunny slope. This trend can be explained as follows. Slope orientation influences soil moisture distribution by influencing the solar radiation received by surface. Sunny slope generally are exposed to solar radiation completely, so the soil moisture is the lowest. On contrary, shady slope is easy to be blocked by mountains and receives less solar radiation, thus having relatively high soil moisture. This conforms to the geographical differentiation law of shady and sunny slopes in geography. TVDI values under different slope orientations in 2017 were higher than those in 2013. The maximum difference (0.13) of TVDI values in 2013 and 2013 was detected on flat slopes. TVDI differences on shady slope, semi-shady slope, semi-sunny slope and sunny slow in 2013 and 2017 fluctuated slightly within $0.05 \sim 0.07$. Generally speaking, soil moistures on different slope orientations in 2017 were lower than those in 2013 to different extent. In a word, shady abrupt slopes at middle and high elevation are the region of forest vegetation in mountainous areas and thereby have relatively higher soil moisture. However, these slopes are typical ecological vulnerable region. Ecologies in these slopes are difficult to be restored once they are destroyed. Hence, it shall try to decrease artificial interference activity, strengthen protection to forest vegetation, planting trees and grasses to increase soil infiltration, lower soil washing by surface runoff, and improve ecological environment in mountainous areas.

\section{Conclusion}

To disclose topographic effect of soil moisture in mountainous areas with complicated topographic conditions, a quantitative inversion of soil moisture in winter in
Dengfeng city, Henan province in 2013 and 2017 is carried out through TVDI method based on Landsat-8 OLI remote sensing images and DEM data as well as NDVI and surface temperature of the study area. Influences of terrain factors on spatial distribution of soil moisture in mountainous region are gained through overlapping analysis of elevation, slope and slope orientation. Based on analysis results, some countermeasures to improve ecological environment in mountainous areas are proposed. This study finally concludes:

(1) Surface temperature in the study area ranges between $-7.16^{\circ} \sim 19.75^{\circ}$ and temperature changes significantly in the whole study area. Generally speaking, surface temperature increases gradually from south-north to middle. Surface temperature in urban areas is about $10^{\circ}$ higher than those in surrounding rural areas and suburbs. This forms significant urban heat island effects. From 2013 to 2017, surface temperature increases dramatically and the distribution range of high temperature expands significantly. The heat island effect has been strengthening continuously.

(2) In 2013 and 2017, drought area accounts for the largest area of total study area, followed by slightly drought area, severe drought area and normal area successively. The wet area accounts for the smallest proportion of the study area. The severe drought area has been expanded mostly from 2013 to 2017, followed by drought area and wet area. Normal area and slightly drought area have been decreased. To sum up, soil moisture in the study area decreases continuously, while drought area expands year by year.

(3) Elevation and slope can influence spatial distribution characteristics of surface soil moisture. With the increase of elevation and slope, soil moisture increases gradually. Effects of slope orientation on soil moisture are mainly manifested by higher soil moistures on shady and semishady slopes, but low on sunny and semi-sunny slopes. Generally, there's an order of soil moisture: shady slope $>$ semi-shady slope $>$ semi-sunny slope $>$ sunny slope.

To sum up, the topographic effect on soil moisture in complicated mountainous region is disclosed by analyzing influences of terrain factors. Theoretical references are provided to formulate water conservation and ecological environmental protection programs in mountainous areas by analyzing distribution laws of soil moisture on different elevations, slopes and slope orientations. Terrain is an important factor that influences soil moisture distribution in mountainous areas. However, spatial distribution of soil moisture is related with surface temperature and vegetation coverage types to some extent, thus resulting in the uncertainty of soil moisture distribution. Influences of surface temperature and vegetation coverage type on soil moisture in mountainous area shall be considered in future studies.

\section{Acknowledgements}

This study was supported by Doctoral Fund of Henan Institute of Engineering (D2016005). The authors are grateful to the student of Henan Institute of Engineering for their support during data processing.

This is an Open Access article distributed under the terms of the Creative Commons Attribution License

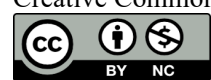




\section{References}

1. Anagnostopoulos, V., Petropoulos, G. P., Ireland, G., Ireland, G., Carlson, T. N., "A modernized version of a $1 \mathrm{D}$ soil vegetation atmosphere transfer model for improving its future use in land surface interactions studies". Environmental Modeling and Software, 90, 2017, pp. 147-156.

2. Leng, P., Song, X. N., Duan, S. B., Li, Z. L., "A practical algorithm for estimating surface soil moisture using combined optical and thermal infrared data". International Journal of Applied Earth Observation and Geoinformation, 52, 2016, pp. 338-348.

3. Mladenova, I. E., Jackson, T. J., Njoku, E., Bindlish, R., Chan, S., Cosh, M. H., Holmes, T. R. H., de Jeu, R. A. M., Jones, L., Kimball, J., Paloscia, S., Santi, E., "Remote monitoring of soil moisture using passive microwave- based techniques: Theoretical basis and overview of selected algorithms for AMSR-E". Remote Sensing of Environment, 144, 2014, pp. 197-213.

4. Yao J., Xue, C. Y., Jiao, F., "Soil moisture retrieval based on Landsat8 OLI image data in the Yanhe river basin". Acta Agrestia Sinica, 26(5), 2018, pp. 1109-1117.

5. Cai, Q. K., Li, E. J., Tao, L. L., Jiang, R. B., "Farmland soil moisture retrieval using PROSAIL and water cloud model". Transactions of the Chinese Society of Agricultural Engineering, 34(20), 2018, pp. 117-123.

6. Njoku, E. G., Chan, S. K., "Vegetation and surface roughness effects on AMSR-E land observations". Remote Sensing of Environment, 100(2), 2006, pp. 190-199.

7. Tao, L. L., Li, J., Chen, X., Cai, Q. K., Zhang, Y. F., “An effective model to retrieve soil moisture from L- and C-band SAR data". Journal of the Indian Society of Remote Sensing, 45(4), 2017, pp. 621-629.

8. Sandholt, I., Rasmussen, K., Andersen, J., "A simple interpretation of the surface temperature/vegetation index space for assessment of surface moisture status". Remote Sensing of Environment, 79(2), 2002, pp. 213-224.

9. Khedri, E., Hasanlou, M., Tabatabaeenejad, A., "Estimating soil moisture using polsar data: a machine learning approach". ISPRSInternational Archives of the Photogrammetry, Remote Sensing and Spatial Information Sciences, XLII-4/W4, 2017, pp. 133-137.

10. Holtgrave, A. K., Foerster, M., Greifeneder, F., Notarnicola, C., Kleinschmit, B., "Estimation of soil moisture in vegetation-covered flood plains with Sentinel-1 SAR data using Support Vector Regression". PFG-Journal of Photogrammetry, Remote Sensing and Geoinformation Science, 86(2), 2018, pp. 85-101.

11. Xue, C. Y.,"Research of regional soil moisture information based on series of Landsat remote sensing images". Doctoral Dissertation of Northwest Agriculture and Forestry University, China, 2017, pp. 6-9.
12. Wolfarth, S. L., Cybis, F. D., Juliano, S., "Two approaches to calculate TVDI in humid subtropical climate of southern Brazil". Scientia Agricola, 75(2), 2018, pp. 111-120.

13. Zhu, W. B., Jia, S. F., Lv, A. F., "A time domain solution of the Modified Temperature Vegetation Dryness Index (MTVDI) for continuous soil moisture monitoring". Remote Sensing of Environment, 200, 2017, pp. 1-17.

14. Yang, R. W., Wang, H., Hu, J. M., Cao, J., Yang Y. "An improved temperature vegetation dryness index (iTVDI) and its applicability to drought monitoring". Journal of Mountain Science, 14(11), 2017, pp. 2284-2294.

15. Jin, C., Qin, Q. M., Zhu, L., Nan, P., Abduwasit, G., "TVDI based crop yield prediction model for stressed surfaces". 2007 IEEE International Geoscience and Remote Sensing Symposium, Barcelona, Spain: IEEE, 2007, pp. 4656-4658.

16. Bai, X., Wang, Z. F., Yang, L. X., "Correlation analysis between soil moisture and environmental factors by remote sensing in upper reach of Heihe river watershed". Remote Sensing Information, 31(6), 2016, pp. 121-127.

17. Yisok, O., Sarabandi, K., Ulaby, F. T., "Semi-empirical model of the ensemble-averaged differential Mueller matrix for microwave backscattering from bare soil surfaces". IEEE Transactions on Geoscience and Remote Sensing, 40(6), 2002, pp.1348-1355.

18. Lievens, H., Verhoest, N. E. C., "On the retrieval of soil moisture in wheat fields from L-band SAR based on Water Cloud modeling, the IEM, and effective roughness parameters". IEEE Geoscience and Remote Sensing Letters, 8(4), 2011, pp. 740-744.

19. Wu, A. B., Pan, L., "Study on relationship between terrain factors and spatial distribution of ecological land in plateau area:taking Bashing plateau of Hebei province as an example". Acta Agriculturae Jiangxi, 30(8), 2018, pp. 101-105.

20. Tian, X., Gao, K., Zhang, L. J., Yu, Y. Q., Han, G. D., "Effects of slope position on spatial distribution of soil water and vegetation in sandy land". Bulletin of Soil and Water Conservation, 35(5), 2015, pp. 12-16.

21. Luo, T. J., "Study on the soil water spatial variability and layout optimization of soil sampling under the small scale". Beijing Surveying and Mapping, (6), 2013, pp. 11-15.

22. Sobrino, J. A., Jimenez-Munoz, J. C., Leonardo, P., "Land surface temperature retrieval from Landsat TM5". Remote Sensing of Environment, 90(4), 2004, pp. 434-440.

23. Qin, Z. H., Karnieli, A., Berliner, P., "A mono-window algorithm for retrieving land surface temperature from Landsat TM data and its application to the Israel-Egypt border region". International Journal of Remote Sensing, 22(18), 2001, pp. 3719-3746. 